\title{
Another proof of wiener's short secret exponent
}

\begin{abstract}
Islam encourages Muslims to discover the remedy for every disease. One hadith stated that the Prophet $(\mathrm{PBUH})$ had suggested use of camel urine to treat his companions who were suffering from abdominal pains at that time. This became a disputed issue among the scholars in determining the legality of treatment with unclean sources such as animal urine and so on. It is generally known that human or animal urine is an unclean source and it is not permissible to benefit from it. The above hadith gave rise to debate among the Muslim scholars, whether it was specific for the Prophet (PBUH), darura (necessity) or it is absolutely permissible till today. In that respect, this article discusses the concept of using animal urine, particularly camel urine, from the scientific and Islamic perspectives. Content analysis of classical and contemporary scholars' views based on research by scholarsd in the relevant field was conducted. Scientific research found that there are diseases which can be treated by using urine. Based on the scientific research, Muslim scholars are divided into three views. Of the three, the selected view is that which regards animal urine as unclean for Muslims to benefit from in the absence of darura (necessity). This means that Muslim scholars still maintain that animal urine is unclean to be used as a method of treatment except on the ground of darura (necessity) to serve a bigger public interest. Results of this research will be of assistance to authorities such as JAKIM and MAIN in dealing with the issue of Malaysian halal certification, especially concerning products which contain urine of animals such as the camel and so on.
\end{abstract}

Keyword: RSA cryptosystem; Continued fractions; Secret exponent; Cryptanalysis; Wiener's theorem 